\title{
Durability of Bricks Cast With Industrial Sludge
}

\author{
G. Reddy Babu ${ }^{1}$, N. Venkata Ramana ${ }^{2}$ \\ ${ }^{l}$ Department of Civil Engineering, Narasaraopeta Engineering College, Narasaraopet, Guntur, Andhra \\ Pradesh, India \\ ${ }^{2}$ Department of Civil Engineering, JNTUA College of Engineering, JNTUA-Anantapur, Andhra Pradesh, India
}

\begin{abstract}
Recovery of waste constituents from industrial waste is a cost effective solution in control of environmental pollution. Present investigation deals with the feasibility of usage of sludge obtained from sand beneficiation treatment plant in the production of bricks and their durability. The experimental results show that the brick earth can be replaced with treatment plant sludge up to $40 \%$ by weight without loss in strength and other brick characteristics considered satisfactory for conventional purposes. Apart from that when reference specimens and test bricks (5\% Sludge) were immersed in various concentrations of hydrochloric acid ( $\mathrm{HCl})$ solution at different immersed ages, the loss of weight is found to be less in test bricks than that in reference bricks. Hence, at 5\% of replacement, the quality of bricks is superior to the bricks made from earth alone and can be used for superior work of permanent nature.
\end{abstract}

Keywords-Brick, Sludge from sand beneficiation treatment plant, Compressive strength, HCL, weight loss

\section{Introduction}

To resolve the apparent conflict between development and environment, several investigations were carried out to reduce or to reuse, recover and to evolve methods for safe riddance of industrial wastes ([1], [2], [3] and [4]). Utilization of industrial wastes in brick making achieves all these objectives simultaneously. It is estimated that presently there are at least 1,00.000 brick fields in India, each manufacturing between 1,00,000 and 20 million bricks per year (www.damleclaystructurals.com). The total number of bricks produced per annum is of the order of 180 billion numbers [5]. Industrial wastes, depending on their composition, may be used in brick making industry to reduce firing temperature, to modify plasticity of the locally available soil or as a filler material in the brick earth. In this investigation an attempt has been made to use the sludge from sand beneficiation treatment plant located at Tada in the brick making while considering its influence on brick standards. Tada is an industrial belt bordering in Andhra Pradesh and Tamil Nadu, pointedly it located between Nellore and Chennai. There are several brick making industries in and around Tada. This industry has been chosen because the use of soil as a construction material falls under the purview of appropriate technology [5] and it is appropriate to use whatever industrial waste available in the vicinity of brick making industry. This will result in multifaceted benefits of reduction in the cost of bricks, improvement of brick quality and economic disposal of sludge from the industry.

\subsection{Sludge from Sand Beneficiation Treatment Plant}

Sand beneficiation treatment plant produces silica sand, which is required for glass industry. In the Sand beneficiation process, after processing the raw material for separation of silica sand, slurry is produced, which becomes solid after drying. The quantity of sludge produced is around 6 to 10 tons per day. The sludge contains predominantly silt and clay sized particles (98.2\%). Its $\mathrm{pH}$ is 5.5 . Liquid limit is $41.5 \%$ and plasticity index $19 \%$. It may be classified as clay of intermediate compressibility (CI) as per Indian Standard Soil Classification System[6].

\subsection{Soil Used}

Traditional burnt bricks are generally made using locally available soil. The soil that is used in this investigation is the one that is being used for manufacturing of bricks at Tada. The soil consists of $52 \%$ of sand and $48 \%$ of silt and clay sized particles. Its liquid limit is $29.5 \%$. Plasticity index $16.5 \%$ and $\mathrm{pH} 7.11$. The soil may be classified as clayey sand as per the Indian Standard Soil Classification System [6].

\subsection{Hydrochloric Acid (HCl)}

Hydrochloric acid was used in different concentrations in order to study the effect of hydrochloric acid on reference bricks and test bricks which are attained maximum strength. 


\subsection{Methods}

In order to study the possibility of using sludge from sand beneficiation treatment plant in brick making, air dried sludge from industry was mixed thoroughly with soil in proportion of 5\%,10\%, 15\%, 20\%, $30 \%, 40 \%$, and $50 \%$ by weight. Water was added to these soil sludge mixes so as to produce a homogeneous paste having enough consistency to mould it into the brick shape by hand. Bricks of size $19 \mathrm{~cm} \times 9 \mathrm{~cm} \times 9 \mathrm{~cm}$ were fabricated from these pastes using hand moulding and soft extrusion technologies as carried out in the brick making industry. The bricks were air dried for 7 days under shade and burnt at $800^{\circ} \mathrm{C}$ in muffle furnace. The burnt bricks, so obtained, were subjected to standard tests viz., efflorescence test, water absorption test and compressive strength test as per I.S: 3495-1976 (Part I to IV)[7] and durability test. Each test was conducted on at least five bricks and their average values were taken for design. The soil sludge mixes were also tested for liquid limit and plastic limit to assess the influence of sludge on plasticity of soil. The plasticity of a good brick earth should lie between 15\% and 25\% (IS: 2117-1975)[8].

In order to study $\mathrm{HCl}$ attack, after 8 days of bricks age, the reference and test bricks (5\% sludge) were immersed in 8 plastic tanks. $\mathrm{HCl}$ concentrations maintained in the tanks were $1 \%, 1.5 \%, 2 \%$, and $4 \%$ respectively. The exposure $\mathrm{HCl}$ solutions were prepared by mixing in deionised water as said above percentages. 12 bricks were immersed in each concentration for up to 30 days. The above procedure was adopted for test bricks. 3 bricks representing similar compositions were retrieved from the opted percentage of $\mathrm{HCl}$ solutions after 7, 15, 21 and 30 days of immersion. The effect of $\mathrm{HCl}$ concentrations on the performance of reference and test specimens was evaluated by measuring the reduction in weight loss. The reduction in weight loss of test bricks was compared with that of reference specimens.

\subsection{Influence of Sludge on Plasticity Characteristics}

\section{Results And Discussion}

The liquid limit, plastic limit and plasticity index of soil sludge mixes were determined adopting methods described in I.S: 2720-1985 (Part 5, reaffirmed in 1995)[9] and are shown in Fig 1. Liquid limit is found to increase with percentage sludge added. Liquid limit of sludge (47.5\%) is more than that of the soil (30.5\%). Hence, the liquid limit of mixes is expected to increase in proportion to the sludge added. However, the plasticity index of the mixes is well within the range of $15 \%$ to $25 \%$, which shall be the plasticity of a good brick earth (IS: 2117-1975)[8]. This shows that the soil-sludge mixes satisfy the plasticity requirements of good brick earth.

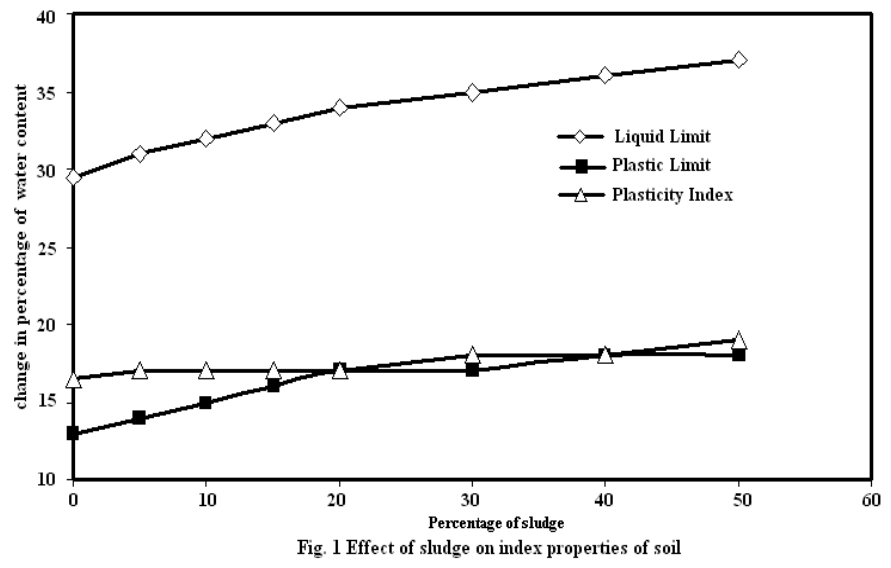

\subsection{Influence of Sludge on Water Adsorption}

The characteristics of bricks, both with and without any addition of sludge to the soil, are depicted in Fig. 2. The fig reveals that the water adsorption is fairly constant up to $10 \%$ sludge but gradually increased with percent sludge thereafter. The Sludge added does possess plasticity and contains silt and clay sized particles which are finer than $0.075 \mathrm{~mm}$. The soil contains predominantly sand. Addition of sludge to soil leads to increase in fine fraction (finer than $0.075 \mathrm{~mm}$ ) which is capable of taking water by adsorption on account of its plasticity and fineness. The water is held at the surface of the clay particles which are electrically active owing to structure and mineralogical composition [10]. The plasticity index and liquid limit of soil sludge mixes are found to be more than, liquid limit and plasticity index of soil alone (Table I). This indicates that water adsorption of mixture will be more than the soil. However, the fine fraction is capable of filling the voids between the bigger sized particles which leads to less pore space and less pore water thereby less water absorption. Hence, the observed water absorption should be sum total of these two effects. The results presented 
in this investigation reveal that the possible increase in water adsorption due to sludge is just offset by possible reduction in water absorption due to reduction in pore space when percentage of sludge added is less than $10 \%$. There is a gradual increase in water absorption, when the sludge added is more than $10 \%$ by weight, indicating that the effect of water adsorption is predominant when the percent sludge added is more than $10 \%$ by weight. The water absorption of bricks rose to $19.23 \%$ when the sludge added is 50\%. According to I.S: 3495 (1976)[7] for the bricks of class up to $12.5 \mathrm{~N} / \mathrm{mm} 2$, the water absorption should be less than $20 \%$ by weight. Hence, it is recommended to limit the percentage of sludge to be added to less than $50 \%$ by weight from the view point of water absorption.

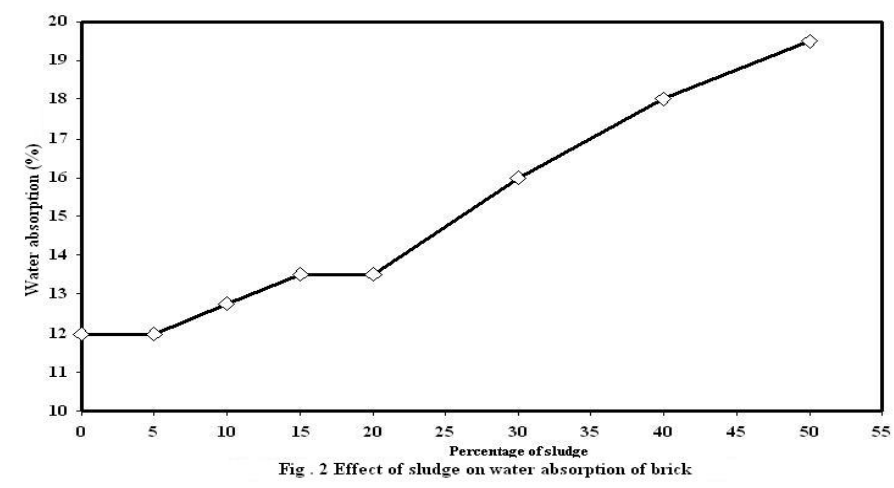

\subsection{Influence of Sludge on Compressive Strength}

Fig.3 illustrates the compressive strength of the bricks tested. The compressive strength of bricks without any addition of sludge is $11.7 \mathrm{MPa}$ Addition of $5 \%$ sludge to the soil increased the compressive strength of bricks to $17.6 \mathrm{MPa}$ about $50 \%$ more than the compressive strength of bricks made of soil alone. However, the addition of sludge beyond 5\% resulted in reduction of compressive strength from 17.6 to $10.5 \mathrm{MPa}$. When the percentage of sludge added to the soil is $40 \%$ by weight, the compressive strength is same as one without any addition of sludge $(11.7 \mathrm{MPa})$. Hence, $40 \%$ of sludge can be added to the soil without any compromise on compressive strength of bricks. If higher strength bricks are required, the proportion of sludge should be kept at $5 \%$ to $40 \%$ depending on the strength requirement ranging from 17.6 to $11.7 \mathrm{MPa}$. The observed changes in compressive strength of bricks due to addition of sludge may be attributed to changes in plasticity characteristics and filler action of sludge. Sludge being finer and having more plasticity than the soil, the addition of sludge to the soil resulted in increased plasticity. The strength is known to decrease with plasticity [11] as it results in lesser friction. Hence, addition of sludge to soil should result in lesser compressive strength of bricks. However, sludge being finer than soils itself, it also may fill the voids within the soil causing reduction in void space thereby making bricks denser. Hence, the filler action of sludge should increase the compressive strength of bricks. The observed changes in strength should obviously be the sum total of these two effects. Filler action is dominant when percentage sludge added is less than 5\%. Further addition of sludge occupies the space only by pushing the coarse sand particles in the soil apart. This will result in reduction in the friction between sand particles which contribute significantly to the compressive strength of bricks. Therefore, reduction in compressive strength is expected at higher percentages of sludge. This is in agreement with the observed change in compressive strength in bricks when sludge added is high.

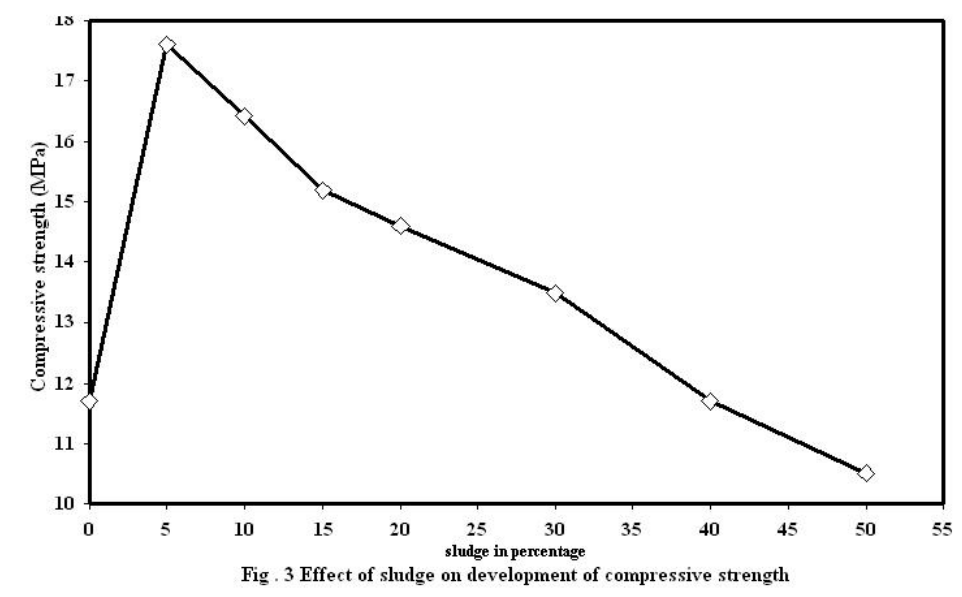




\subsection{Hydrochloric acid attack}

Figs. 4 and 5 show reference bricks and test bricks (5\% Sludge) immersed in 1, 1.5, 2.0 and $4 \%$ hydrochloric acid solutions for 30 days. The decrease in compressive strength, with increase in concentration and period of exposure, is noted in reference and test specimens. The decrease in compressive strength is less in test bricks when compared that of reference bricks for any concentration of hydrochloric acid solution. However, at $4 \%$ of $\mathrm{HCl}$ solution, the decrease in compressive strength is by $9.5,14.85,18.50,20.25 \%$ in reference bricks and $8.25,13.50,17.30,18.85 \%$ in test bricks for $7,15,21$, and 30 days respectively.
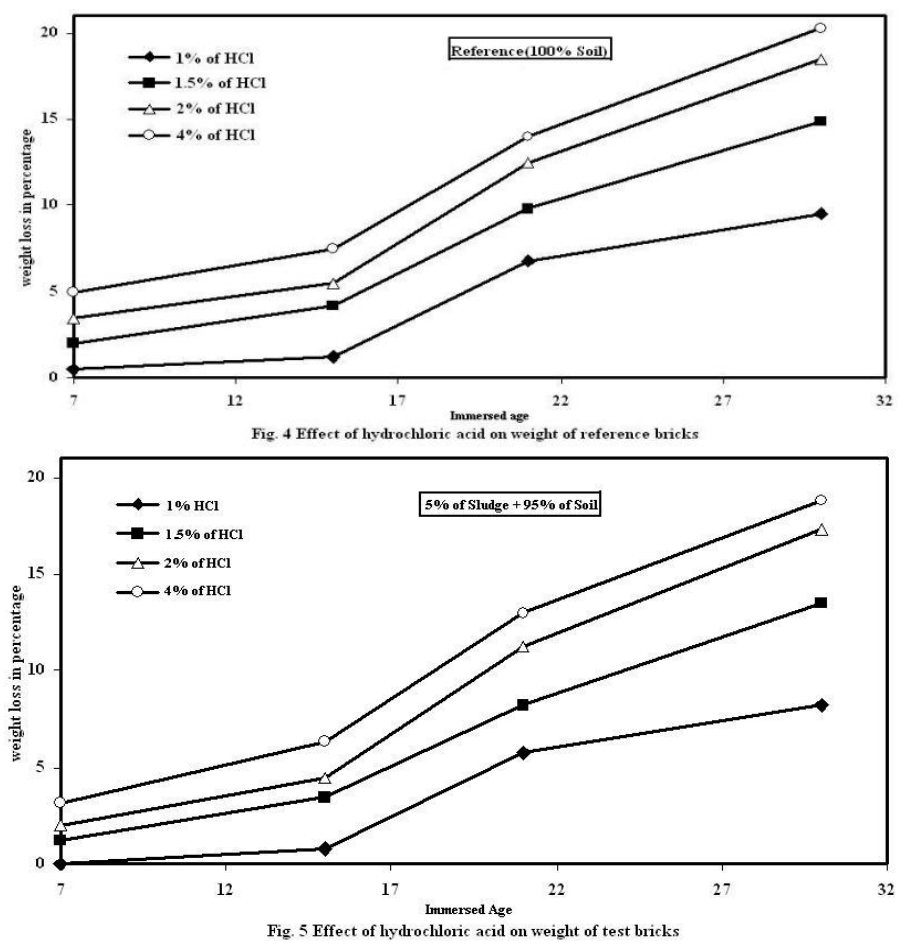

IV. Conclusion

Sludge generated from sand beneficiation treatment plant can effectively replace bricks making earth up to $40 \%$ by weight without any compromise on brick characteristics like water absorption, compressive strength and efflorescence. The addition of sludge to the soil serves the twin benefits of safe disposal of sludge from industry and conservation of brick making earth. Test bricks are more durable than reference bricks. The sludge produced each day from sand beneficiation treatment plant will be sufficient to make 5000 to 8000 bricks at $40 \%$ ' replacement by weight.

\section{References}

[1] Bhattacharya. J.K. Shekdar. A.V. and Gaikwad, S.A. 2004. Recyclability of some major industrial solid wastes. Journal of Indian Association for Environmental Management, 31(1): 71-76.

[2] Kotaiah. B.. Ramana Reddy. I.V. and Sreedhar Reddy, S. 2002. Ceramic tile industrial waste treatment plain-residue usage in the production process. J. Curr. Sci., 2(1): 73-74.

[3] Subramanyam, K. 1999. Fly ash, Fly ash and Cement in Compressed Soil blocks. M.Tech. Thesis Submitted to Sri Venkateswara University College of Engineering, Tirupati.

[4] Kotaiah, B. 1990. Management of Liquid Waste of Stiles India Limited. Unpublished Project Report, pp. 32.

[5] Madhava Rao, A.G. and Ramachandra Murthy. D.S 1996. Appropriate Technologies for Low Cost Housing. (Oxford \& IBH)

[6] IS: 1498-1970. (Reaffirmed 1992). Classification and Identification of Soil, BIS. New Delhi.

[7] IS: 3495-1976. Part 1 to IV. Methods of Tests of Burnt Clay Building Bricks. BIS, New Delhi.

[8] IS: 2117-1975. Guide for Manufacture of Handmade Common Burnt Clay Building Bricks. BIS. New Delhi.

[9] IS: 2720-1985. Part V. Determination of Liquid Limit and Plastic Limit. BIS. New Delhi.

[10] Mitchell. J.K. 1976. Fundamentals of Soil Behaviour, (John Wiley and Sons. Inc... New York).

[11] kempton. A.W. 1957. The Bearing capacity of clays. In: Proceedings of Building Research Congress. 